\title{
Use of Photogrammetry for Digital Surveying, Documentation and Communication of Cultural Heritage. The Case of Virtual Reconstruction of the Access Doors for the Nameless Temple of Tipasa (Algeria)
}

\author{
BAYA BENNOUI-LADRAA, National Center for Archaeological Research, Algeria \\ YOUCEF CHENNAOUI, Polytechnic School of Architecture and Urbanism, Algeria
}

\begin{abstract}
This paper presents a methodological contribution to the field of the process of archaeological restoration based on virtual anastylosis. In particular, we treat the reconstruction of fragments of the nameless Temple of Tipasa in Algeria. Our work is focused more specifically on the virtual restoration of the three access doors into the temple's sacred courtyard. Here, we have found many fragments, including the voussoirs, which were revealed during excavation, encouraging the development of our hypothesis about the original condition of the temple. The protocol followed is based on the photogrammetric survey of the blocks, which has allowed us to generate 3D models of the elements constituting the entrance facade into the sacred courtyard. The historical documentation as well as architectural treatises made it possible to fill in the gaps in the evidence with the aim of reconstructing the temple as best as can be done. The main objective of the research was to provide a corpus of data in 2D and 3D of all the blocks which served, at first, for the documentation and the study of the remains. Secondarily, the same documentation proved useful for development of a hypothesis of virtual reconstitution for making more comprehensible to the general public the history of the site of Tipasa.
\end{abstract}

Key words:

Photogrammetry, 3D Reconstruction, Virtual Anastylosis, Corpus, Temple.

SDH Reference:

Baya Bennoui-Ladraa and Youcef Chennaoui. 2018. Use of Photogrammetry for Digital Surveying,

Documentation and Communication of Cultural Heritage. The Case of Virtual Reconstruction of

the Access Doors for the Nameless Temple of Tipasa (Algeria). SDH, 2, 2, 121-137.

DOI : $10.14434 /$ sdh.v2i2.24496

Authors' address: Baya Bennoui-Ladraa, Centre National de Recherche en Archéologie (CNRA), Rue Hocine Beladjel, 16003 Algiers, Algeria; email: b.bennoui@cnra.dz and bennouib@gmail.com; Youcef Chennaoui, École Polytechnique D'Architecture et d'Urbanisme d'Alger (EPAU), Beau Lieu, El-Harrach, Algiers, Algeria; email: y.chennaoui@epau-alger.edu.dz and chennaoui_youcef@yahoo.fr.

(c) [2018] by the authors; licensee Studies in Digital Heritage, IU, Bloomington (IN), USA. This article is an open access article distributed under the terms and conditions of the Creative Commons Attribution License (CC BY-NC). 


\section{2:122 B. Bennoui-Ladraa and Y. Chennaoui}

\section{INTRODUCTION}

The interpretation of cultural heritage and its communication to the general public have always been major concerns for scientists and managers involved in the development and conservation of cultural property. Long criticized or even banned, physical anastylosis, whose main goal was to communicate an accurate visualization of the ruins, has, unfortunately, affected the integrity and thus the authenticity of cultural property. Virtual anastylosis has two advantages: it compensates for the almost inevitable side effects of an archaeological excavation, viz., the destruction of the site in its pristine condition, and it also offers a valid alternative to physical restoration, which reduces the authenticity of historical monuments. For this reason, we propose the relatively new method of virtual anastylosis for the interpretation and the communication of a cultural heritage monument while, at the same time, preserving its material and historical integrity. Restoration is accordingly perceived in a new, virtual dimension, which emancipates itself from constraints related to the difficulties of physical interventions. Not least of these is the fact that a virtual restoration can be easily updated or modified, as new archaeological data come to light-something not nearly as easily done in the case of physical anastylosis. The archaeological interpretation is, then, expressed in a new vision developed according to a scientific and methodical approach. The field of research on archaeological restoration and the field of the new technologies for the virtual presentation of cultural heritage are closely linked. However, computer-based visualization must be always at the service of archaeological heritage, rather than the reverse (cf. Principle 2 of The Seville Principles of Virtual Archaeology).

The present work exemplifies this new approach, the fundamental principles of which are defined in the London and Seville Charters, which provide a point of reference in the field of digital visualization of heritage, and that must be part of a strategy of access and sustainability. This implies the need in all work of interpretation and communication of cultural heritage for all the documentation used for the restoration to be made publicly available, including the documentation of research sources, the documentation of the methods used, as well as the justification of the chosen method [Apollonio 2016]. The example chosen to support this approach is the project of virtual anastylosis of the northern portico of the sacred enclosure of the nameless temple on the archaeological site of Tipasa in Algeria, located around 80 kilometers west of Algiers and classified by UNESCO in the list of World Heritage Sites in 1982 (Fig.1).

The excavated remains of the temple and its courtyard are located in the western part of the archaeological site at the intersection of two Roman roads: the cardo and the decumanus maximus. The construction probably dates from the second, or at the latest, of the third century CE. The temple stands at the end of a rectangular courtyard with three porticoes, in the center of which are the substructures of the sacrificial altar. It is a sacred enclosure that frames a large quadrilateral whose long sides are located to the east and west. The temple itself is located south of the quadrilateral in the north-south median axis. Of the northern portico, along the decumanus, there remain only two blocks of stone, once part of the main facade. The design of the façade included two corner pilasters and six middle pilasters. It is through this portico that the sacred courtyard of the temple was entered through three access doors, the central of which is the largest.

Studies in Digital Heritage, Vol. 2, No. 2, Publication date: December 2018 


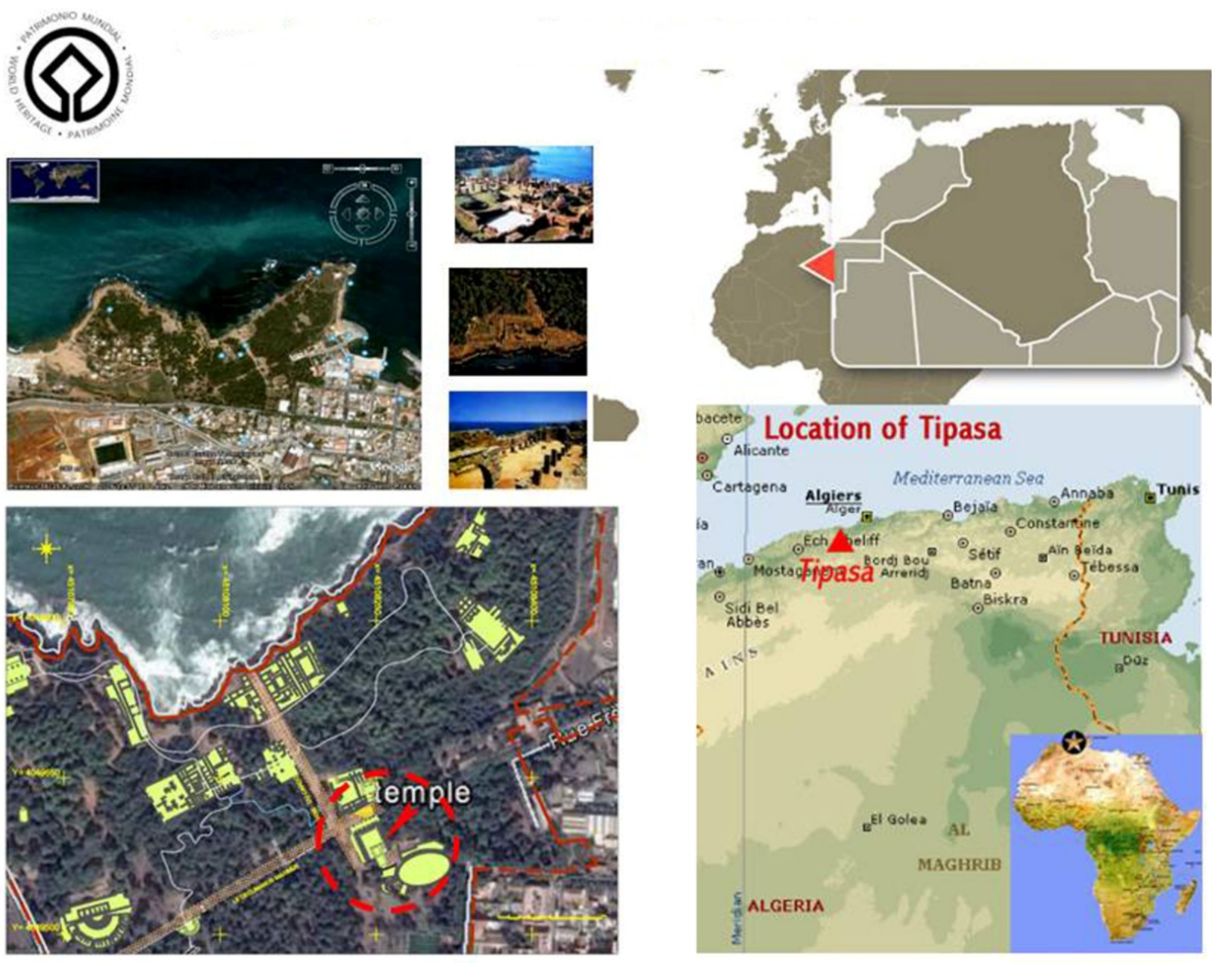

Figure 1. Location of the nameless temple of Tipasa.

During the excavation work carried out in 1859 by the Historic Monuments Service and by A. Ballu in 1922 [Ballu 1922] and S. Gsell in 1926 [Gsell 1926], several fragments belonging to the temple were found, including cornices, architraves and voussoirs, belonging to the temple and the three porticoes. The fragments forming the voussoirs of the northern portico and its entablature are now seen near the access doors to the sacred courtyard (Fig. 2).

The abundance of the collected fragments, among them the voussoirs forming the arcades of the doors, supports the work of virtual anastylosis. This approach is encouraged by the development of techniques of study and documentation of cultural heritage, based today mainly on photogrammetry and laser scanning. In our case, data acquisition was performed using photogrammetry, which provided a comprehensive body of 2D and 3D digital models of the stone fragments from the three northern gantry doors found during excavation work. 


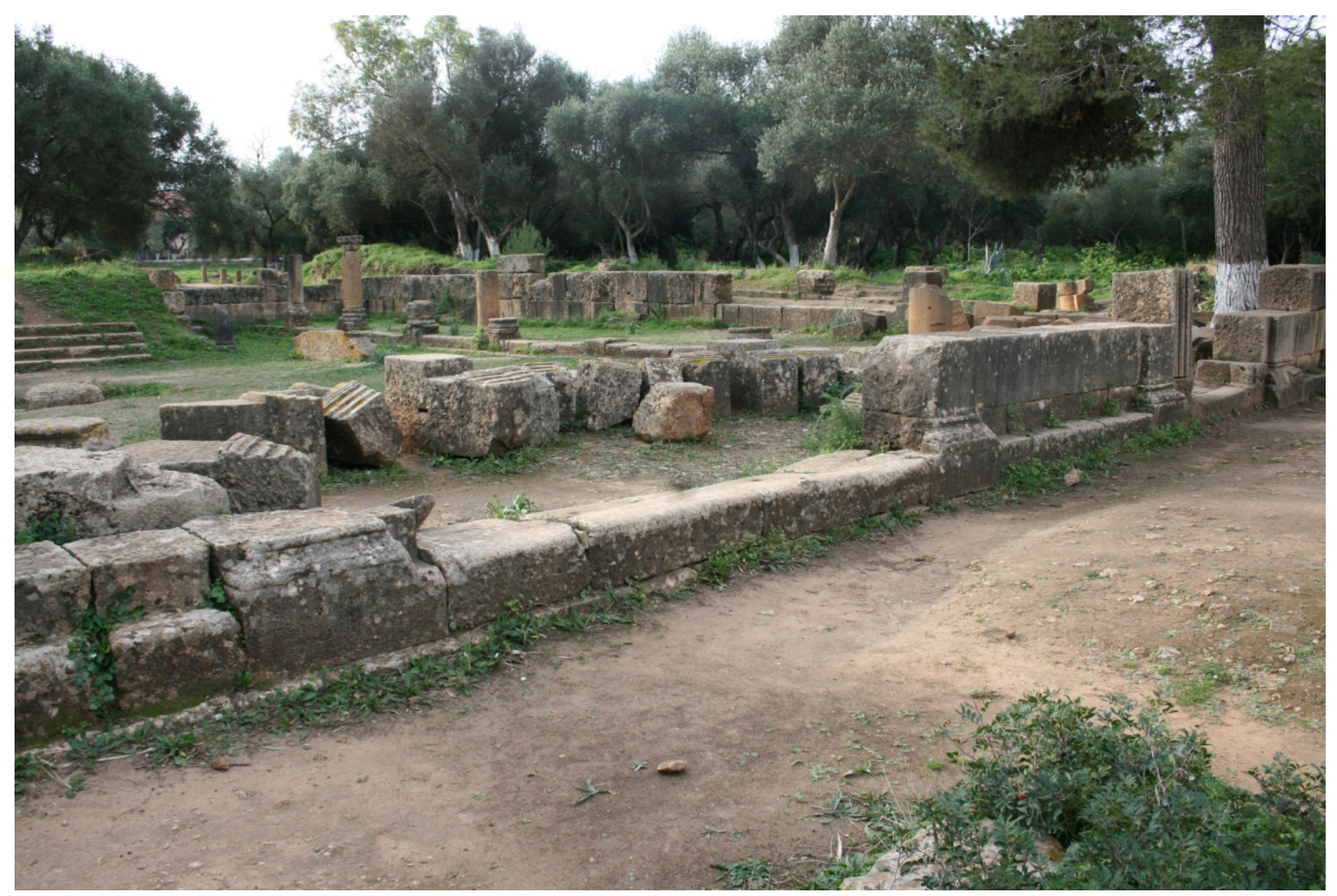

Figure 2. The fragments of the voussoirs of the arches discovered during the excavations and currently grouped near the northern portico.

Semantic research according to the basic forms defined in architectural treatises provided a threedimensional textured ideal model of each fragment and which led to the development of a proposal for virtual anastylosis of the arches of the entrance gates to the sacred precinct of the temple.

\section{MATERIALS AND METHODS}

Prior knowledge of the area to be studied is essential in any work of virtual restoration of monuments and archaeological sites. This first phase brings together as much information as possible about the subject, and the material gathered can help explain the facts on the ground. For this, we used first an overall geo-referenced and scale plan showing the state of the ruins as well as all the scattered architectonic elements found during excavation work [Bennoui et al. 2017]. Subsequently, the work focused on the northern portico, where fragments of the blocks of keystones, cornices, architraves and other elements were collected. In the beginning, the blocks of stones were carefully cleaned from dust, grasses and other residues, and then targets were placed that were surveyed with the Total Station for use at a later stage (Fig.3). 

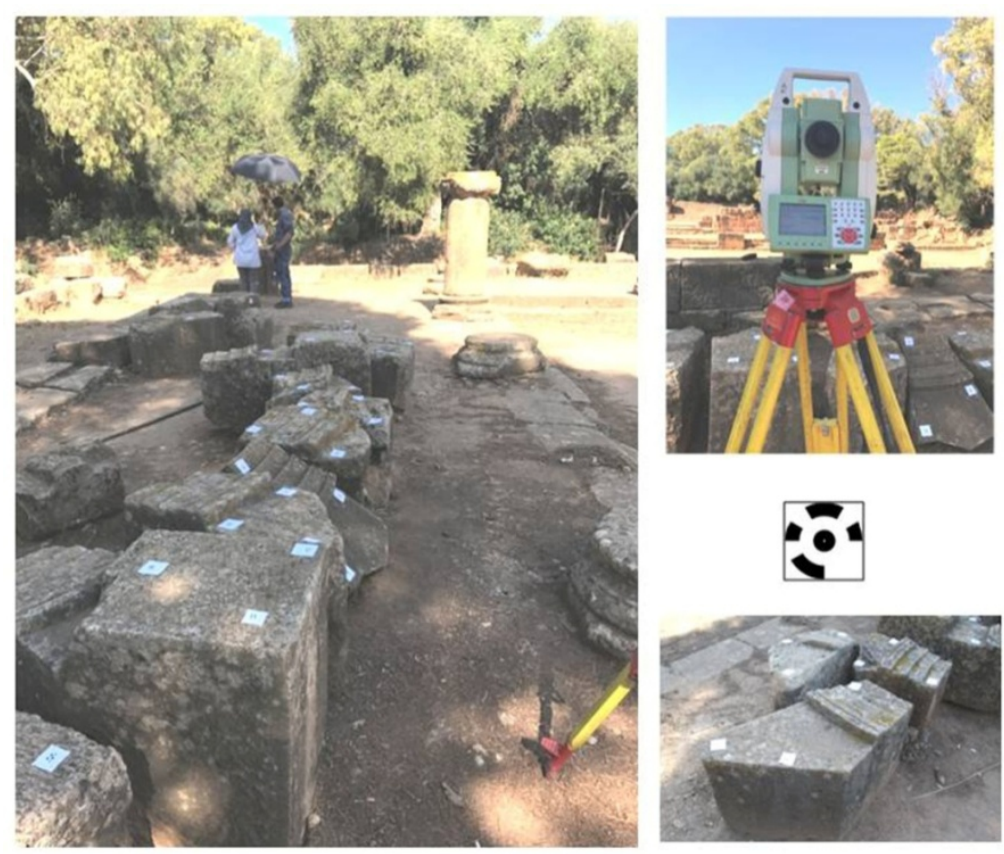

Figure 3. Use of the Total Station (Leica Total Station ST 11) for the survey of the targets placed on the stone blocks (a minimum of three targets is necessary to generate orthophotos at a later stage).

The photogrammetric survey was carried out using a digital SLR camera (Canon EOS 1000D), and the targets identified allowed the creation of a corrected photograph of the portico, which served as a basis for the inventory of architectural elements (Fig.4).

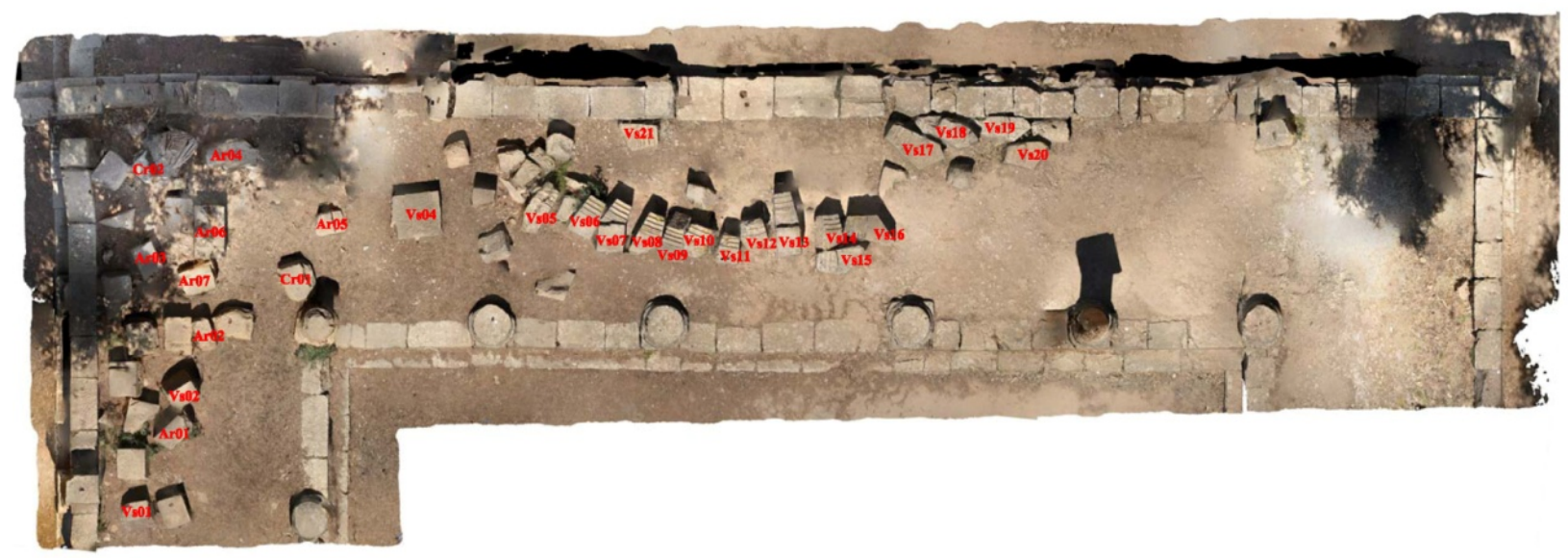

Figure 4. Orthophotography of the northern portico showing the state of ruins and scattered blocks.

The inventory used the identifiers VS, Ar, Cr, meaning that the block belonged, respectively, to a keystone, an architrave or a cornice (Fig.5). Excluded from the inventory are blocks of stone without 
moldings and damaged ones whose state of wear does not make it possible to extract the information necessary for the study.
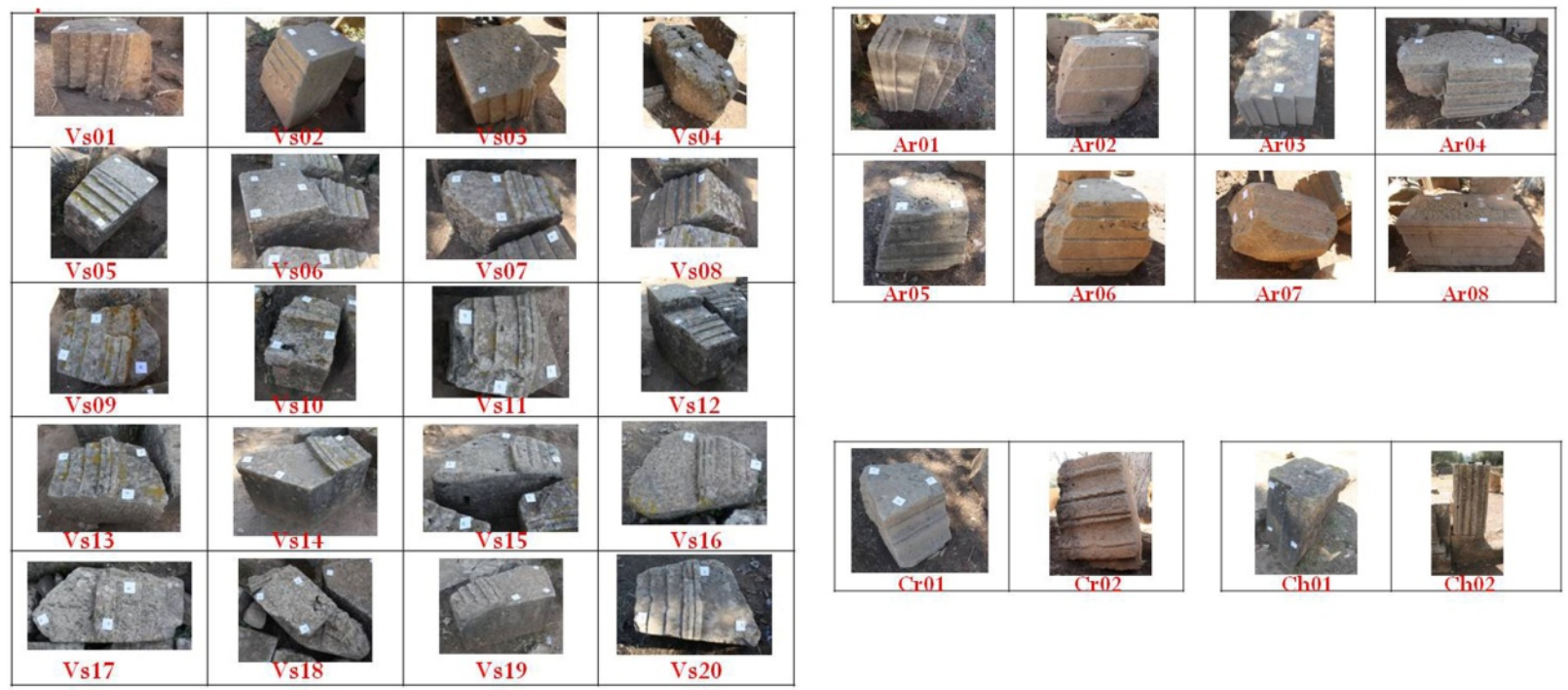

Figure 5. Corpus of blocks found on the site: the voussoirs (to the left), the architraves (top right) and the cornices and door jambs (bottom right).

Several protocols have been developed to establish a methodology for the virtual anastylosis of elements belonging to an archaeological site based on 3D modeling of fragments. The approaches are based on the technical digital image of the fragments found in the site, which makes it possible to reproduce a 3D model that represents a hypothetical copy of the original model on the basis of such historical knowledge as known shapes and typologies, old building rules, documentation, etc. [Fuchs et al. 2004; Cancianni et al. 2013].

For the present work, the analysis protocol followed three main stages.

\subsection{State models}

After this preparatory work, a photographic campaign was carried out, taking care to keep the focal length fixed, the zoom off, the sensitivity set to the lowest level and following the recommendations of CIPA 3x3 rules for taking pictures [Waldhäusl and Ogleby 1994]. As sunlight can cause significant clipping areas on the block surfaces, special care has been given to protect the blocks against solar exposure. Each fragment was isolated to obtain a 3D model of its current state, or condition, with maximum resolution. The result was the creation of a three-dimensional mesh and textured model from which measurements could be made. Thanks to the targets placed on the surface of the blocks, it was possible to generate a orthographically correct image of each element. A comprehensive 2D and $3 \mathrm{D}$ corpus of all the blocks surveyed was developed with the possibility of extracting useful measurements for a comparison of the fragments in each family of keystones, cornices, and architraves. This made it possible to distinguish subcategories in which were grouped elements 
having the same morphological characteristics that aided in the later virtual anastylosis. Two subcategories in the corpus of keystones were distinguished: first subcategory included the keystones adorned with an archivolt whose profile presents three steps of ca. $8.50 \mathrm{~cm}$ with no separating moldings crowned by a right ogee, followed by a flat band.

a)
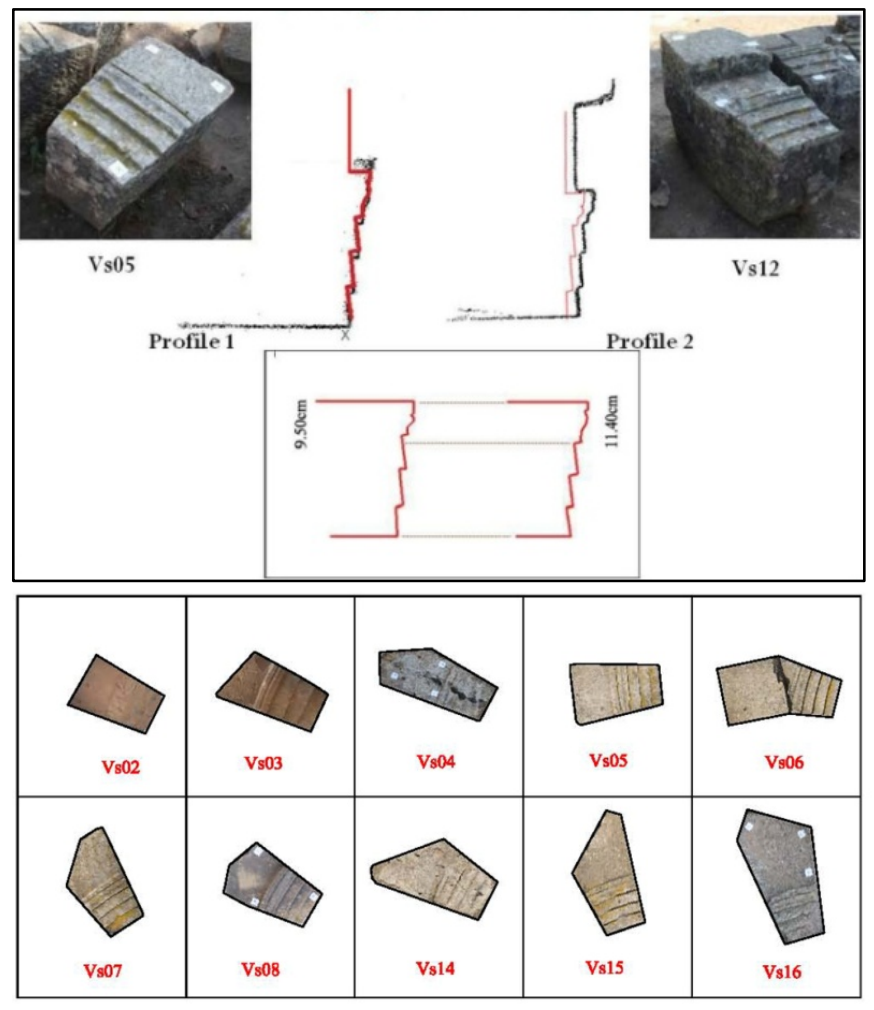

Sub-category 1

b)

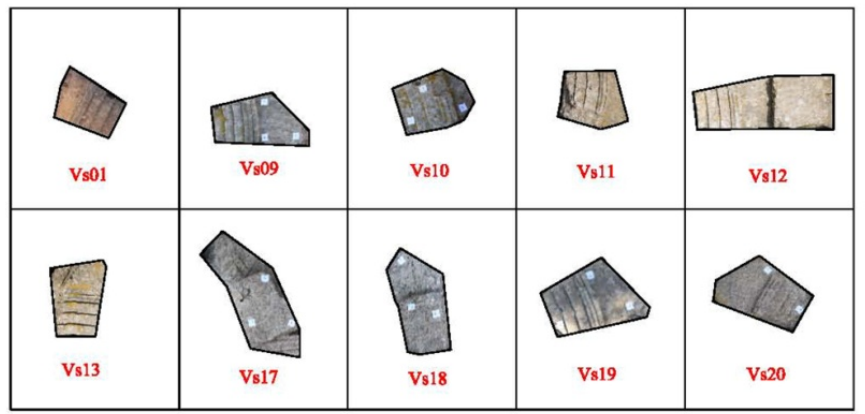

Sub-category 2

Figure 6. a) Profile of the voussoirs extracted from the cut made on the point cloud in AutoCad software. Two types of profiles can be distinguished on the basis of their different crowns; b) Corpus in 2D (orthophotos) of the two subcategories of voussoirs. The first includes the blocks forming the arch of the main door, and the second those of the two secondary doors. 


\section{2:128 B. Bennoui-Ladraa and Y. Chennaoui}

This crowning section measures $11.40 \mathrm{~cm}$ for the first subcategory. In the second subcategory, we find the same description and the same measurements except for the crown, which measures 9.50 cm (Fig.6).

\subsection{Restoration, or "Ideal" Models}

So far, the 3D models generated reflect the state of the elements as they currently exist with all the imperfections related to wear, weather, erosion and other factors. This fact makes the interpretation of basic morphology difficult. It was thus necessary to proceed to a semantic reading based on the analysis of the moldings which form the smallest architectonic unit [Fuchs et al. 2004]. Classical architectural treatises are, therefore, essential sources of reference to understand the logic of decomposition from the synthesis of theoretical elements.

The work, therefore, started with extracting from the point clouds the raised elements of the sections made in the axis of symmetry at the most perfectly preserved place. The profile of the moldings was drawn for each piece based on the elementary classification of the moldings according to their geometric characteristics [Fuchs 2004]. This resulted in the generation of a perfect profile consisting of the succession of several typical moldings (Fig. 7). All that remained was to extrude the profile and complete the molding of the block according to the measurements extracted from the model as entered. A second corpus of blocks was then created with the realistic 2D and 3D models of all blocks of stones belonging to the northern portico (Fig. 8). This database was used to perform the virtual anastylosis taking into account the morphology of each element.

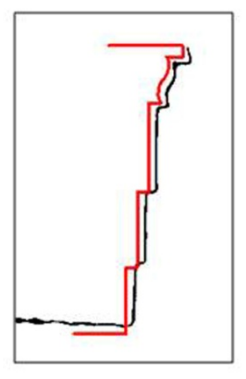

a

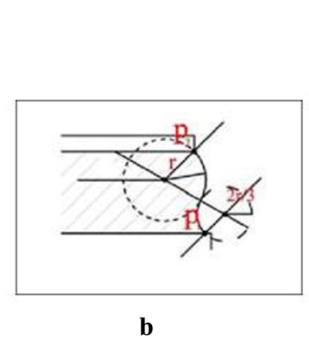

b

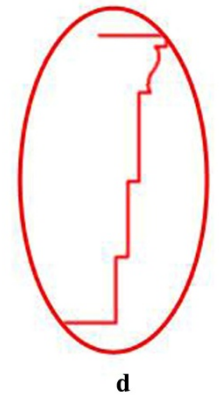

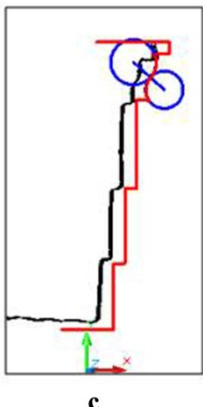

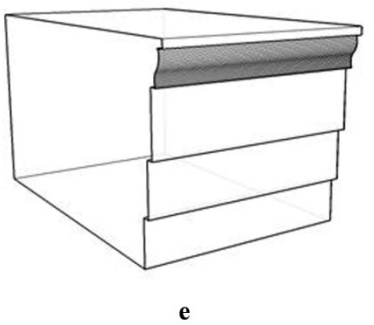

Figure 7. Analysis of moldings and classification according to geometric characteristics: a) extraction of the profile from a section made along the axis of symmetry in the point cloud; $b$ ) analysis and research of typical moldings; c) elementary classification of the moldings according to geometric characteristics; d) perfect profile according to semantic analysis; e) Profile extrusion to obtain the realistic model (as built). 


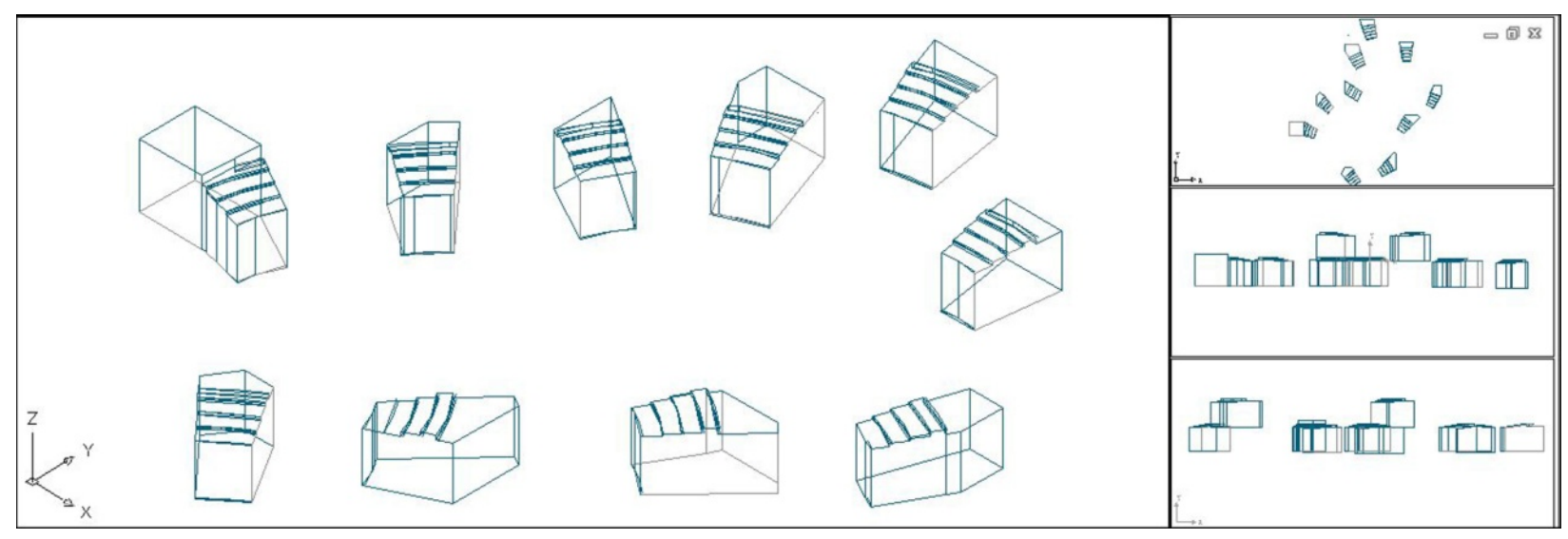

Figure 8. Different views of realistic models of voussoirs in AutoCad.

\subsection{Virtual Restoration}

This was perhaps the most interesting, but also the most complex, step of the project. During it, we moved from planimetric restoration to restoration in elevation by using both the corpus of architectural blocks and the architectural knowledge contained in the architectural treatises.

In plan, it is possible to easily distinguish the span of the arches of the three doors. Based on the corrected image from the photogrammetric survey of the northern portico, it was, indeed, possible to record several metric data that provided a first idea of the arch spans over each of the three doors. Thus, the main door is about $3.80 \mathrm{~m}$, while the secondary doors on the east and west are about $1.95 \mathrm{~m}$ (Fig. 9).
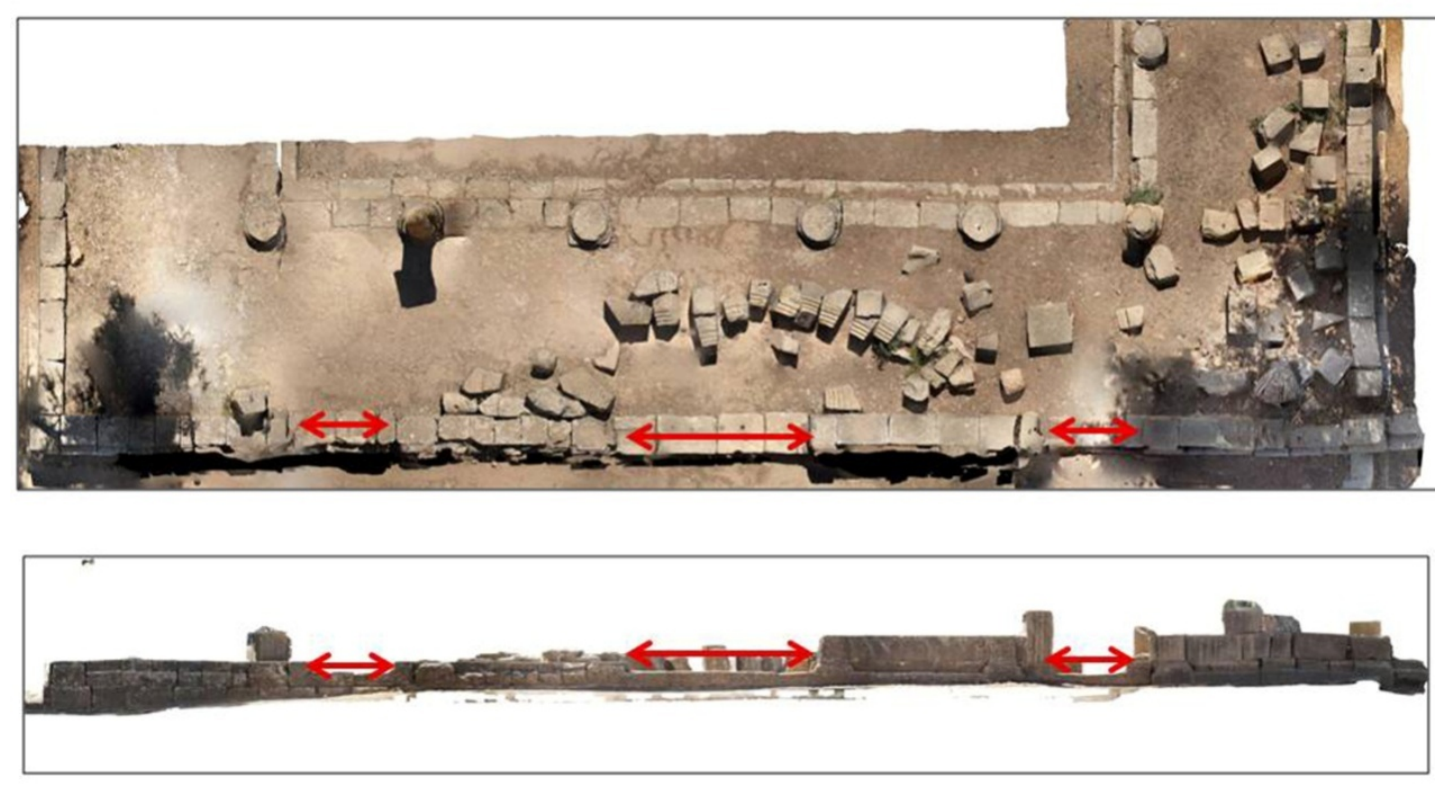

Figure 9. Location of the access doors identified on the orthophotos of the ruins made with Photoscan. 


\section{2:130 B. Bennoui-Ladraa and Y. Chennaoui}

Considering that the technique of building arches in Roman times was based on semicircular arches and comparing the case study to similar examples belonging to the same geographical and historical context, the restoration of the arches in elevation over all three access doors was completed without difficulty. As for the restoration of the height, recourse to the rules of construction of the classical architecture was essential. The classical order of architecture imposed geometric relations between the radius of curvature of the circle which composes the plot of the arch, the span of the arch and its height in a fixed ratio. For the Corinthian order found here, the ratio was 1:1.97 from pilasters with pedestals [Chitham 1985]. (Fig.10).

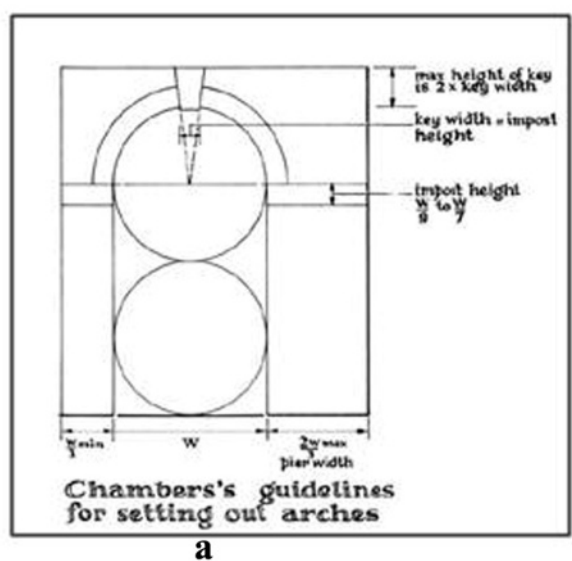

Figure 10. Reconstruction of the elevation in accordance with architectural treatises and virtual anastylosis of the access: a) proportions of openings for the Corinthian order [Chitham 1984: fig 64]; b) example of the virtual anastylosis of the arch over the main door; c) restoration of the elevation.

Since the arches of the three doors had been drawn, all that remained was to place the keystones into their original position on the curve of the lower surface using the models in the corpus of the keystones. Given that we had two different subcategories, the graphical environment of Autocad was used to test the hypothetical restoration of the key elements compared to the layout of large and small arch. The curved section of the keystones of the first subcategory with a wider finishing crown was in perfect agreement with the dimensions of the arch over the central door. This is logical given the size and importance of the central door which was to receive the most prominent archivolt. Thus, after having drawn the curve of each arch, the profile of the stones of each subcategory was moved towards the curve of the intrados until it perfectly fit the curvature. During this phase of the work, the curvatures of the archivolt types helped a lot in the restoration of the blocks to their original location.

Taking into account the dimensions of the blocks, it was, therefore, possible to reconstruct the doors with a total of fifteen voussoirs for the main door and eleven voussoirs for each of the secondary doors.

We next proceeded to the virtual anastylosis of the blocks. The shape of cut of the blocks, different from one block to another, helped in determining the direction the blocks were laid in relation to the set. 


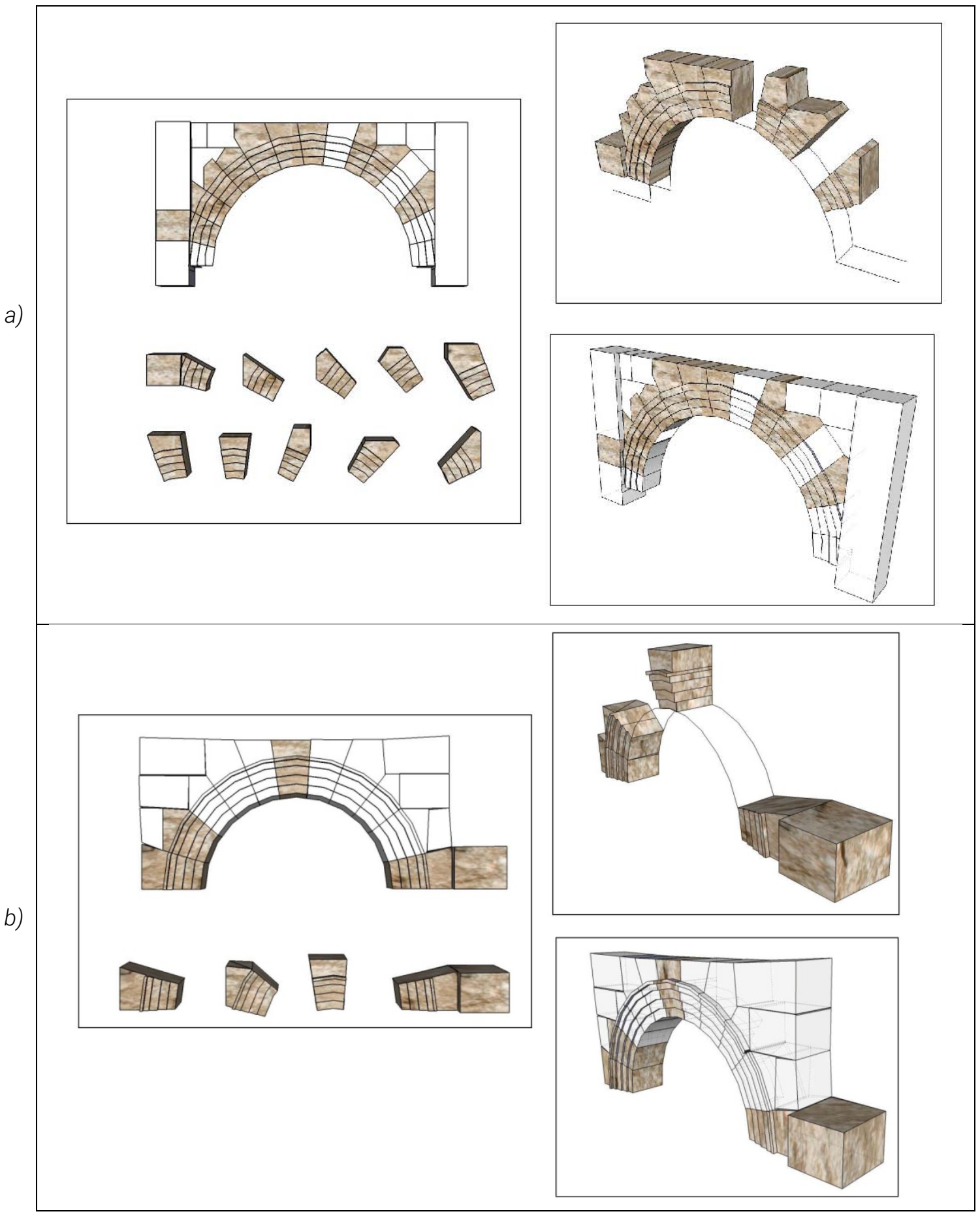

Studies in Digital Heritage, Vol. 2, No. 2, Publication date: December 2018 


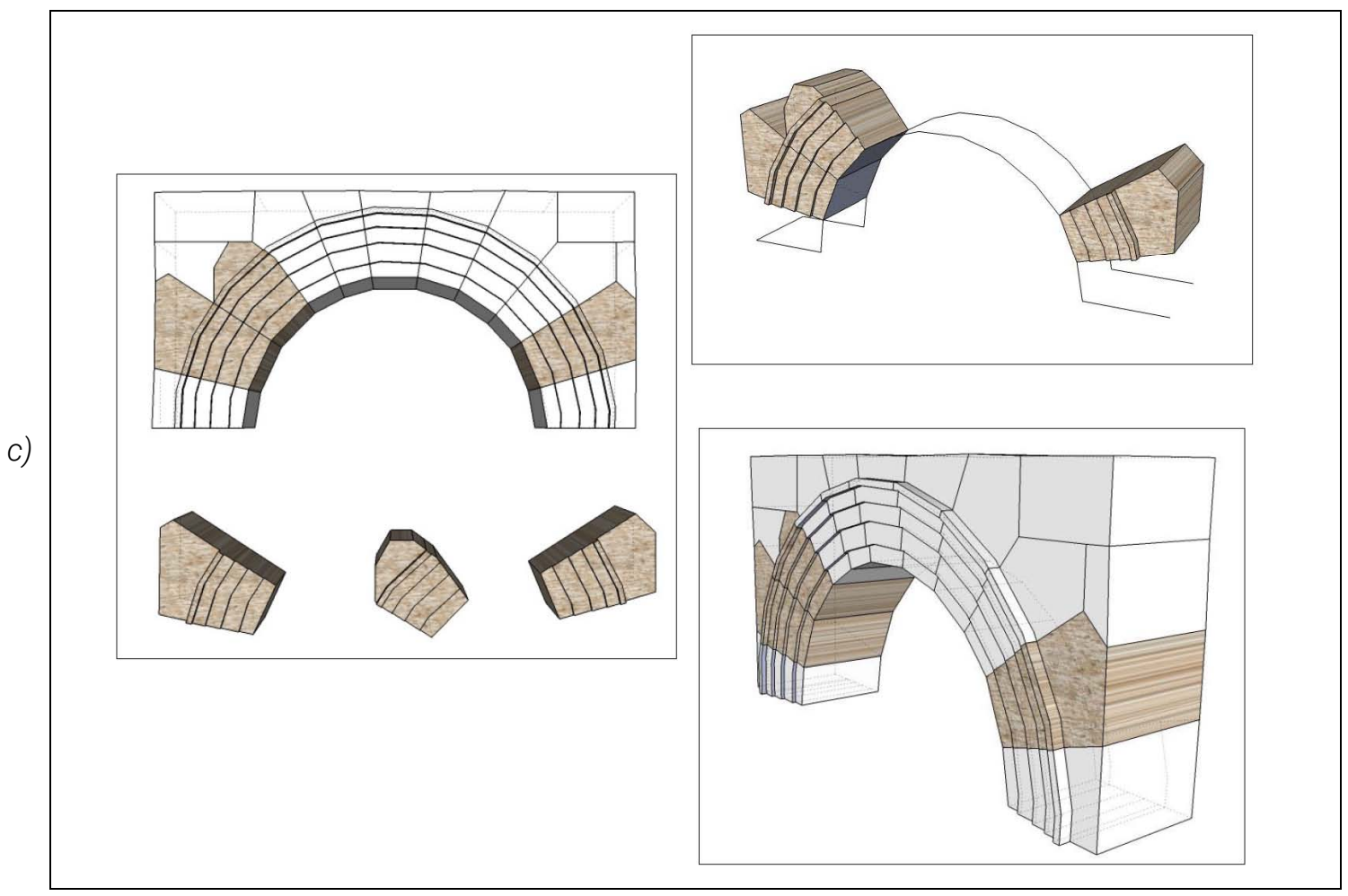

Figure 11. Virtual anastylosis of the three access doors: a) the first secondary door; b) the main door; c) the second secondary door.

This made it possible to identify the blocks belonging to the springers, the archstones, or the keystones. Another interesting element was the presence of traces of fitting used for lifting the stones because these could confirm in which direction the block was laid (the trace of the rectangular groove used for the lifting of the stones must be on the upper surface). The work thus led to a first stage corresponding to the virtual anastylosis of the blocks surveyed on site for each of the three points of access (Fig. 11).

In a final step of the work, the missing keystones were virtually restored in a three-dimensional virtual computing environment. There are twenty of these blocks, five for the main door, eight for the east secondary door, and seven for the west secondary door.

To obtain the virtual model of each block, the arches were first drawn, including the details of the moldings of the archivolts with the replacement of the raised blocks in their place of origin. Some blocks found on the site have valuable details that provided information about the depth of the penetration of the arch $(\mathrm{ca} .8 .5 \mathrm{~cm})$.

Indeed, the typology study with the comparative analysis of the arcs of doors carried out on the geographical space of the Ancient Maghreb, enabled us to suppose the presence of a fore-part. This latter represents a basic element in the formal and structural composition of the African arcs; what had thus authorized us to declare that there was a recourse again to the entablature in this period. 
Our hypothesis is consolidated by the presence in-situ of two blocks of architrave. They present the same dimensions which are identical to the blocks of the voussoirs, which were surveyed.

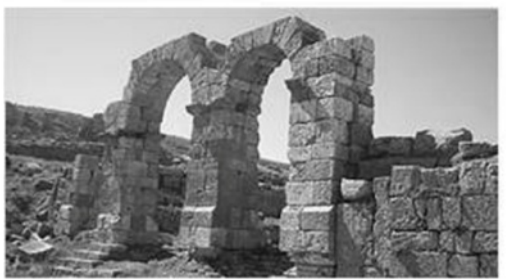

Arc of Madaure (Khamissa) Algeria

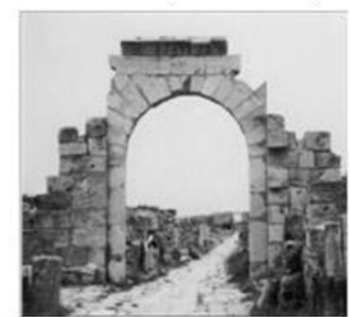

Arc de Tib ère Lepsis Magna (Libya)

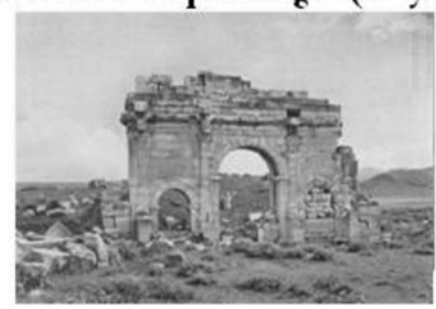

Arc of Zana (Algeria)

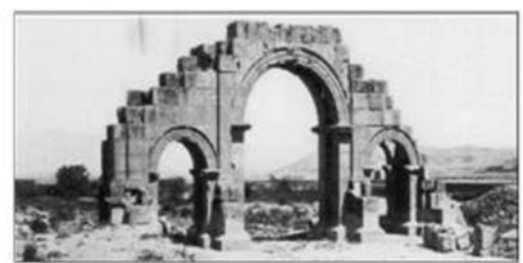

Arc of Lamb èse (Batna) Algeria

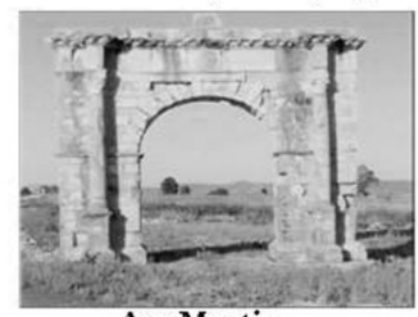

Arc Mustis

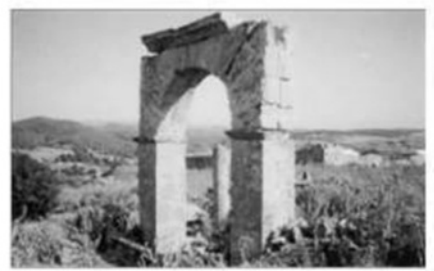

Arc K'sar El Kaoua-Algeria

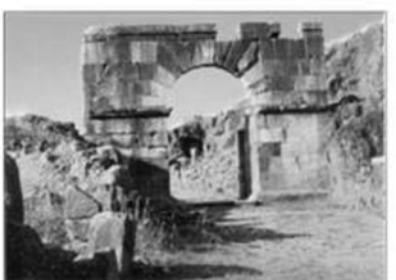

Arc of Memius (Tiddis)-Algeria

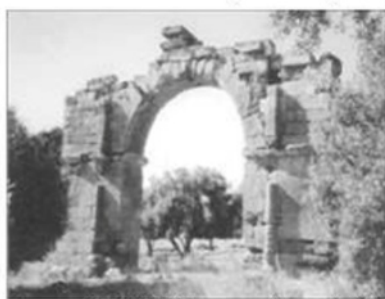

Arc of Althiburos (tunisia)

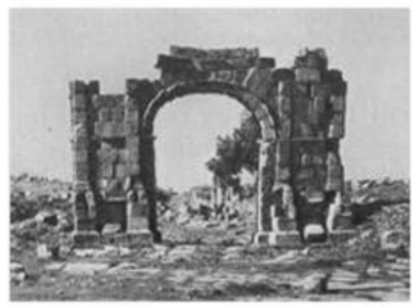

Arc of Announa-Algeria

Figure 12. Similar examples belonging to the same geographical context and of the same period.

All that remained was the restoration of the entablature and the attic, some fragments of which were identified among the blocks lying on the ground near the northern portico. These included several blocks forming the architraves, the pieces of two types of cornice (the larger probably belonged to the entablature, and the other to the attic) as well as some elements of the jambs (carved pedestal).

First, we proceeded to the restoration of the entablature, consisting of the following elements:

- an architrave restored from the blocks found on site. A realistic 3D model has been created consisting of three fasciae and a final band consisting of an upturned ogee and a fascia;

- a cornice which superimposes a bandeau, a cavet, a right ogee, and a listel.

As for the frieze, no fragment was found on the site. Therefore, its restoration had to be carried out on the basis of Vitruvian rules [Vitruve 2006].

In the second phase of the work, restoration of the attic had, likewise, to be based on the assumption that it had the same return as the entablature. In this case, the second type of cornice was chosen. It consists of a cavet, a bandeau, a soffit-cut drip edge, a straight ogee, a bandeau, with all the moldings 
separated by a listel. The gaps have been filled in virtually in accordance with the architectural treaties.

The project thus led to the reconstruction of the three entrance gates of the nameless temple on the basis of a 3D virtual anastylosis that simultaneously integrated the planimetric and altimetric restorations. The first is based primarily on field data, while the second combines information from in situ elements combined with historical documentation, valuable parallels from architectural treatises, and comparison with comparable monuments [Canciani et al. 2013] (Fig. 13).

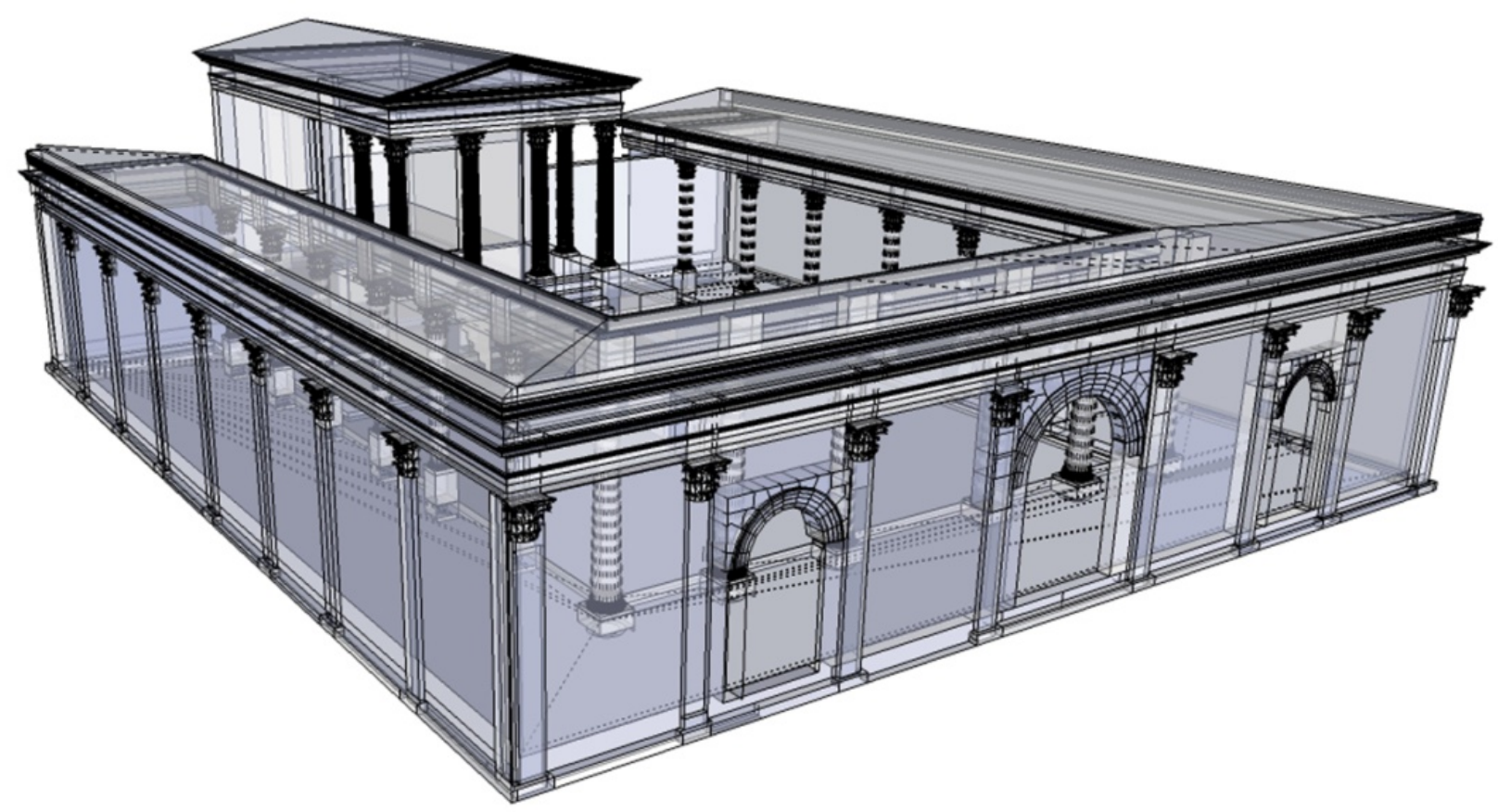

Figure 13. Hypothetical restoration of the temple and the sacred enclosure.

\section{RESULTS}

The project led to the stone-by-stone virtual rendering of the main entrance facade of the nameless temple that stands along the decumanus. The facade consists of three bays; the main one is higher than the other two. The arches of the doors are made of ribs extradossed in fasciae and decorated with archivolts thus exemplifying the model of the arches of North Africa during the same period.

The survey technique used was photogrammetry, which provided a comprehensive database of point clouds needed to produce orthophotographs and 3D models that can be measured and used according to the desired scales or research themes. The establishment of a model represents an essential phase in the transition from the phase of collecting raw data to a representation that goes beyond purely metric considerations to a semantic interpretation of the data [Bennoui et al. 2017]. Indeed, the digital and technical tools used were indispensable in all phases of the research: survey, 
ideal geometric establishment of a model based on semantic structuring of moldings, hypothetical restoration, and exploitation of information.

During this process of analysis and research, in addition to the three-dimensional textured model (which remains the fundamental support in all the work), it was necessary to acquire for each single fragment specific information to guide the work of anastylosis, including: its orientation with respect to its original position, its contiguity or similarity with other fragments, the characteristic section of the moldings, determination of the bearing and contact surfaces, etc.

The main objective of this work was to provide archaeologists with an operational tool that could support their field research and documentation activities, especially when it came time to interpret fragments found during excavation activities.

The proposed protocol is thus organized in relation, on the one hand, to spatial data that can be used to produce unprocessed models as entered and, on the other hand, to descriptive, historical and theoretical information that will generate the ideal models as well as constructs and virtual models that help in formulating restoration hypotheses of the archaeological remains.

The choice of plotting in the form of a virtual image resulted from the fact that 3D graphic development software is today an essential and increasingly popular tool for the visualization of cultural heritage [Barceló 2000; Apollonio 2016].

The perspective of this research is the development of specific algorithms which will help the automation of the process and thus the evaluation of the hypothetical virtual anastylosis. The algorithm that will be developed will allow the precise repositioning of the blocks in their original location but also the automatic creation of the missing voussoirs.

\section{DISCUSSION}

Through the example of the restoration of the northern portico of the nameless temple of Tipaza we wished to show the efficiency of modern instruments of survey and 3D modeling in the documentation, interpretation and communication of the archaeological heritage, especially at the time when the three-dimensional visualization of cultural heritage has become very popular. [Kolenda and Markiewicz 2017].

The methodology followed in this study is part of a larger vision that considers an archaeological interpretation to arise from a thoughtful and considered framework based on generally-agreed scientific and methodical conventions. Thus, the proposed final virtual model does not represent an end in itself, since it remains hypothetical and therefore evolutionary or even modifiable, but rather a tool to test an approach whose main objective remains the proposal of a study protocol and analysis for the appreciation and communication of archaeological heritage.

The body of 2D and 3D data from the photogrammetric survey can be the basis of metrological and/or proportional surveys to establish typological and comparative studies for the development of studies and research on similar monuments. In this sense, and in an access strategy as suggested in the charters of London and Seville, our goal is to make it possible for the entire the scientific community 


\section{2:136 B. Bennoui-Ladraa and Y. Chennaoui}

to use the database resulting from this work. Here we may cite Archeovision's Archeogrid online database as an example of what we have in mind.

Dissemination of all the documentation used (documentation of research sources, graphic documentation, corpora of 2D and 3D data, hypotheses of restoration) will allow an exchange of ideas concerning study, interpretation and management. It will also allow the evaluation of the work from data collection and analysis to the final result.

Given that the reconstruction of ancient monuments and, especially, the reassembly of a site according to the layout and design it had in a given historical epoch are ever more common practices in archaeology, we hope that this study may be an example of good practice showing how open research and open data can foster virtual anastylosis when cultural heritage is at risk or otherwise difficult to study because key data no longer are extant.

\section{REFERENCES}

Fabrizio I. Apollonio. 2016. Classification Schemes and Model Validation of 3D Digital Reconstruction Process. Proceedings of the 20th International Conference on Cultural Heritage and New Technologies 2015 (CHNT 20, 2015). Vienna. Available at: www.chnt.at/wpcontent/uploads/eBook_CHNT20_Apollonio_2015.pdf

Albert Ballu. 1922. Rapport sur les travaux de fouilles et de consolidations, exécutés par le service des monuments historiques. Algiers: Ancienne maison Bastide-Jourdan.

Juan A. Barceló. 2000. Visualizing What Might Be: An Introduction to Virtual Reality Techniques in Archaeology. Juan A. Barceló et al., eds. Virtual Reality in Archaeology. Oxford: Archeopress, 936.

Richard Beacham et al. 2008. An Introduction to the London Charter. Available at: www.londoncharter.org/fileadmin/templates/main/docs/beacham-denardniccolucci_intro.pdf

Baya Bennoui-Ladraa et al. 2017. "Contribution to the Technical Interpretation of the Roman Sacred Architecture by the New Survey Methods: Case Study - The Nameless Temple of Tipasa, Algeria." Handbook of Research on Emerging Technologies for Architectural and Archaeological Heritage. IGI Global, 2017. 132-158. Web. 27 Jan. 2018. doi:10.4018/978-1-5225-0675-1.ch005

Marco Canciani et al. 2013. "A Method for Virtual Anastylosis: The Case of the Arch of Titus at the Circus Maximus in Rome." ISPRS Annals of Photogrammetry, Remote Sensing and Spatial Information Sciences, Volume II-5/W1, 2013, 61-66.

Robert Chitham. 1985. The Classical Orders of Architecture. Rizzoli, 1985.

Alain Fuchs et al. 2004. "Confrontation du relevé laser 3D aux techniques de relevé conventionnelles et de développement d'outils numériques pour la restitution architecturale." Revue Française de Photogrammétrie et de Télédétection, Société Française de Photogrammétrie et de Télédétection, 2004, 36-47.

Pierre Grussenmeyer et al. 2002. "Architectural Photogrammetry: Basic Theory, Procedures, Tools. " Chapter in Digital Photogrammetry, edited by M. Kasser and Y. Egels, Taylor \& Francis (2002), 300-339.

Stephane Gsell. 1926. Promenades archéologiques aux environs d'Alger. Paris: Les Belles Lettres. Justyna Kolenda and Małgorzata Markiewicz. 2017. "The Medieval Bishop's Palace in Milicz. 3D 
Reconstruction as a Method of a Research Hypotheses Presentation." SDH, 1, 2, 428-443. DOI: 10.14434/sdh.vli2.23458

Anne-Marie Leydier-Bareil. 2006. Les arcs de triomphe dédiés à Caracalla en Afrique du Nord. http://docnum.univ-lorraine.fr/public/NANCY2/doc275/2006NAN21026_1.pdf

Donald M. Rattner. 1998. Parallel of the Classical Orders of Architecture. Vol.3. Acanthus Press. Robert Vergnieux. 2011. Archaeological Research and 3D models (Restitution, validation and simulation). L'usage scientifique des modèles 3D en archéologie. De la validation à la simulation. In Virtual Archaeology Review [S.1.], 2, 4, 39-43, may 2011. Available at: https://polipapers.upv.es/index.php/var/article/view/4546. Date accessed: 28 jan. 2018 doi:https://doi.org/10.4995/var.2011.4546.

Vitruve. 2006. Les dix livres de l'architecture. Translated by Perrault. Paris: Erance.

Peter Waldhäusl and Cliff Ogleby. 1994. "3-by-3- Rules for Simple Photogrammetric Documentation of Architecture." In: J. G.Fryer, editor, Close Range Techniques and Machine Vision. Proceedings of the Symposium of Commission V of ISPRS in Melbourne, Australia, 1-4 March 1994. IAPRS XXX/5, 1994, 426. Available at : http://cipa.icomos.org/wpcontent/uploads/2017/02/CIPA__3x3_rules__20131018.pdf

Tipasa's Plan of Protection and Enhancement of Archeological Sites and Their Buffer Zones (PPMVSA), CNERU October 2010

Archive Plans found in the OGEBC archive (Office of Management and Exploitation of Cultural Goods) located in the Palais des Raïs, Algeirs, Algeria

Received September 2018; revised October 2018; accepted December 2018. 